\title{
Household Socio-Cultural and Economic Predictors of Drug and Substance Abuse among High School Students in Kisumu East Sub County, Kisumu County -Kenya
}

\author{
Marceline A Orende $^{1}$, Daniel O Onguru ${ }^{1}$, David O Odongo ${ }^{2} \&$ Marion A Muranda $^{1}$ \\ ${ }^{1}$ School of Health Sciences, Jaramogi Oginga Odinga University of Science and Technology (JOOUST) Bondo, \\ Kenya \\ ${ }^{2}$ In-depth Research Services Institute of Health and Social Work Nairobi, Kenya \\ Correspondence: Marceline A Orende, School of Health Sciences, Jaramogi Oginga Odinga University of Science \\ and Technology (JOOUST) Bondo, Kenya. P.O. Box 210-40601. Tel: 254-78-750-6670/ 254-72-454-2257.
}

Received: November 29, 2020 Accepted: December 10, 2020 Online Published: January 3, 2021

doi:10.5539/gjhs.v13n2p104

URL: https://doi.org/10.5539/gjhs.v13n2p104

\begin{abstract}
Purpose: The household socio-cultural and economic predictors of drugs and substance abuse among high school students were investigated in Kisumu East Sub-County, Kisumu County.

Study Area Description: The study was conducted in Kisumu East Sub County in Kisumu County within the community set up. The area has approximated total population of 220,997 with an area of 141.6 sq.km density of 1560 per sq. $\mathrm{km}$ with a total number of 61,388 households. It is made up of five wards and 12 village units. The area has a total of 33 secondary schools with a total population of 26,000 students out of which 12,800 are males and 13,200 females. Out of 33 schools, 28 are day schools drawing students from the community. The main economic activities are quarrying, motorcycle ride, small scale businesses and farming. There is high rate of drop out of school among students due to the availability and accessibility of drug and substance abuse in the area as well as the geographical location. There are homes where bhang as well as local brew is sold at affordable cost.
\end{abstract}

Methods and/or Techniques: This was a descriptive cross-sectional study. The study targeted high school students aged 15-25 years learning within the study area. Sample size of 434 was calculated using Yamane formula and the participants selected through Snow ball, random, cluster and stratified sampling. Demographic characteristics were summarized using tables while inferential statistic done using Chi square, binomial logistic regression and multiple regression. Data collection done through observation and questionnaires. $\mathrm{P}$ value $<0.05$ was considered statistically significant.

Results: Parental expectations, psychological disorders or mental problems, family background, leisure activities and festivities, number of siblings in the family, cultural beliefs and practices, birth position of the student, family shock and the need to treat certain ailments were found to be significantly associated with the abuse of drugs and substance $(p<0.05)$.

Conclusion: Lack of parental/guardian's supervision and monitoring of the students movements, poor parent-child attachment due to inadequate family time, no communication on the dangers of drugs and substance abuse to students by the parents and high academic expectations by parents/guardians from students are the major contributors of drugs and substance abuse among students.

Keywords: abuse, drug; economic, high school, Kisumu East sub-county, predictors, social-cultural, students, substance

\section{Introduction}

Globally, it is estimated that drug-related deaths account for between 0.5 and 1.3 per cent of all-cause mortality for people aged 15-64 years. There are 211,000 drug-related deaths annually, with younger people being at high risk (WHO, 2019). According to the world drug report, 37,000 people die annually in Africa due to consumption of illegal drugs and substances. The Drug and Illicit Substance Abuse problems in sub-Saharan African countries have however been attributed to the spill-over effect from Europe and Americas where Africa occupies the second position worldwide in trafficking and consumption of illegal drugs (World Drug Report, 2014). Currently, 11.7\% 
of young people aged 15-24 are users of alcohol, $6.2 \%$ use tobacco, $4.7 \%$ khat while $1.5 \%$ are users of cannabis. Regrettably, this age bracket constitutes youths in Kenya some of whom are students in either secondary schools or higher institutions of learning thus depriving the country its energetic population that could otherwise be producing the best of the economy's goods and services (Chesang, 2013).

Statistical information from Kisumu district hospital and provincial director of medical services indicates increase in mental and behavioral disorders due to multiple drug use and use of other psychoactive substances; the high number of out -patient psychiatric cases in Nyanza could be attributed to bhang use. In 2010, cases of mental and behavioral disorders due to multiple drug use and use of other psychoactive substances among secondary school age (15-24 years) admitted in the hospital were three which increased to ten in 2011. Out patients psychiatric cases alone were 4137 in 2011 of which $90 \%$ were from Kisumu district hospital. The percentage increase is $233 \%$ and continues to increase yearly in Kisumu town (Nyatuoro, 2012). However, there is very little information on the household predictors for drug and substance abuse among high school students in the area. This therefore justified the need for this study that sought to investigate the household predictors of drug and substance abuse among secondary student in Kisumu East sub-county, Kisumu County, strategies by parents/ guardians in addressing the same and come up with the possible policies to address the problem

Financial capability of the young generations plays a critical role in their accessibility to illicit drugs and substances. For instance, a substantial number of students aged 13 - 17 years in several national and private schools in Kuala Lumpur, Selangor, and Negeri Sembilan admitted that they are drug abusers. Most of these students come from middle and upper class families hence given unnecessary generous amount of pocket money per month which they use to easily obtain illegal drugs (Sajjadi et al., 2015; Shahraki et al., 2019). Similarly in Kenya, studies have revealed that family economic set up of a child influences his/her habits in that, students who receive more pocket money tend to engage more in drug abuse to an extent of converging with friend for alcoholic drinks during weekends and holidays than their counterparts who get less pocket money (Njoki, 2013; Simatwa et al., 2014). In the contrary, financial constraint in the family contributes towards students' drug abuse. Adolescents from poor families are pushed in to drugs by the situation at home which makes it difficult for their parents to provide for their needs. This stressful situation at home make them resort to substance abuse as a way of coping with their problems not realizing the negative consequences involved while some parents are compelled to work far away from home, leaving their children in the care of grandparents who cannot monitor their movement (Mohasoa \& Fourie, 2012). Moreover, low income and high unemployment levels make some parents to brew alcohol as a source of income generation with their children as sellers while others allow their children to engage in drug and substance peddling as long as they received something for family use which in due course expose them to drug and substance abuse. Additionally, busy work schedules and long working hours of family members leads to limited family time for parents to bond and supervise their children (Gale et al., 2012; NACADA, 2012; Mukhandia, 2014; Simatwa et al., 2014).

Cultural tolerance of some drugs and substances can as well contribute to child's drug and substance abuse for instance. Studies in Uganda by (Stafström \& Agardh, 2013; Abbo et al., 2016) revealed that most tribes in Uganda have a culture of brewing alcohol in homes thus exposing the youth to alcohol consumption at an early age while in Kenya, there are cultural norms among various communities that expose individuals to drug and substance abuse at very early age. For example, some cultures openly promote and recommend taking of stimulants, depressants and hallucinogens such as beer, liquor, wine, tobacco and cannabis sativa during particular important cultural and ceremonial occasions like marriage, memorial services, initiation and circumcision. During such events, people are grouped in age sets and provided with the drugs and substances of their choice opportunity that most of the youth get to have a taste of the substance and with more frequent tasting of the substance, they get addicted. Moreover, the ceremonies have unchecked drinking that goes unchallenged while some parents indulge in drug use in the presence of their children (Kasundu et al., 2012; Simatwa et al., 2014).

According to study by Hernandez and Araiza, (2014), family stressor such as poor health care, bereavement, divorce and domestic abuse, mistreatment of children, including sexual, physical abuse and neglect equally contribute to drug and substance abuse since they make adolescents feel helpless pushing them to take refuge in drug and alcohol as a way of coping with extreme stress and hostile home environment. The findings further reveals that, ease of accessibility of alcohol or drugs in the house as well as parents who abuse substances to cope with stress do influence the children in to the habit through imitation of the learned behaviors since the drugs are within their reach while teens who perceive their parents as permissive toward drugs and alcohol are more likely to use these substances than teens who felt their parents disapproved of the behavior. Loss of parents and being raised in a dysfunctional family seems to contribute a lot to abuse of illicit drugs whereby students who stayed with friends or alone had higher odds of using alcohol and other drugs than students who stayed with their family 
(Kalula, 2011). Similarly, adolescents from child-headed families proved to be at risk of substance abuse because they do not have anyone to guide them or provide moral support during this challenging stage of development. The study further reveals that permissive parenting style also contributes to substance abuse in that adolescents from such families are free to use substances because no one corrects or reprimands such behavior or even guides them while authoritative parents who do not allow their children time to relax may frustrate them making them to take refuge in drugs (Mohasoa \& Fourie, 2012; Kiambi, 2018; NACADA, 2019).

Parents who involve their children in drug use either by asking them to get them a beer or to light a cigarette, increase the likelihood that teens will use or abuse drugs since youth are more apt to get involved in alcohol use when parents are tolerant of children's use with few or in consistent rewards for non- use (Olumide et al., 2014). Moreover, a household with one cigarette smoker doubles the likelihood that a teen will smoke or expect to smoke since young people learn from what they see by imitating what their parent and other significant people in the community do; the stronger the relationship between an individual and their drug user relatives, the higher the risk of him/her becoming a drug user (Shahraki et al., 2019). However, modelling of drug use by older siblings appears to be a better predictor of a younger brother's use than parental use (Cheloti, 2013; Chebukaka, 2014). This study therefore investigated household socio-cultural and economic predictors of drug and substance abuse among secondary students in Kisumu East sub-county, Kisumu County in order to help in formulation of policies and designing relevant programs aimed at addressing drug and illicit substance abuse among learners.

\subsection{Statement of the Problem}

According to Kisumu county director of education, drugs and substance abuse is on the increase from $7 \%$ in 2009 to $15 \%$ in early 2019 with the highly affected area being Kisumu East sub-county where many students drop out of school due to drug and substance abuse either through suspension or health challenges associated with drugs and substance abuse for instance mental illness and organ damage (Kisumu County Education Director, 2019). However, it remains unclear why students still engage in this risky behavior. It is against this background that this study was undertaken to establish the household predictors of drugs and substance abuse among secondary students and come up with appropriate solution to the problem in the area.

\subsection{Justification of the Study}

Kenya, like many other developing countries, is faced with the social problem of high rates of drugs and substance abuse. Unfortunately, the percentage of substance abusers in schools increases yearly despite the efforts to eradicate the problem (Nyassy \& Kihara, 2008). Substance abuse amongst adolescents may lead to poorer health as well as negative social consequences such as cancer, depression, personality disorder, unintentional injuries, unplanned sexual activity and increased sexually transmitted diseases (Griffin et al., 2019). Study by Mohasoa and Fourie (2012) revealed that Substance abuse among adolescents and youth costs a country a lot of money every year this is reflected in the large sums of money spent on prevention and treatment centers instead of economic investment which if left unaddressed goes a long way to frustrate the attainment of the Sustainable development Goals as well as the vision 2030 which aims at making Kenya industrial and mid-level income country.

A report by Kisumu District Hospital indicates an increase of $233 \%$ annually right from 2010 with majority being of age bracket of (15-24 years) using illicit drugs and psychoactive. In 2011, outpatient psychiatric cases alone were 4137 of which $90 \%$ were from Kisumu district hospital (Nyatuoro, 2012). The escalating rate of drug and substance abuse puts the county at a risk of losing productive generations as well as underdevelopment due to the diversion of resources to address basic needs for dependents young adults, increased health care needs among the youth abusing alcohol and drugs. If the vice is left unchecked, there will be high crime rate and loss of future generation. Hence the need to conduct a study on the household predictors of drugs and substance abuse among high school students within Kisumu East sub-county with an aim of awareness creation to the community at large and come up with ways of addressing the challenge.

\subsection{Significance of the Study}

The study findings will help in awareness creation to the students, community and nation at large on the dangers of illicit drug and substance use aimed at achieving positive behavior change hence influence them to adopt healthy lifestyles free from drugs. Through this, the adolescents and the youth will be saved from the negative consequences of drugs and substance abuse which will be of benefit to the country in saving the future generation. The households will also benefit from the findings through early detection of the household predictors for drug and substance abuse among children and prevent them before addiction. The outcome of this study will also be important in guiding formulation and implementation of policies on drugs and substance abuse among students as well as in the designing or development of suitable prevention / intervention strategies aimed at curbing drug and 
substance abuse among students and the youth in all learning institutions in Kenya. Moreover, the study findings will contribute to the addition of new knowledge to the existing knowledge base on illicit drug and substance abuse for readers and future researchers.

\section{Summary of Methodologies in Literature Reviewed}

From the reviewed literature, various methodologies were employed in collecting data on drug and substance abuse among high school students based on the study area, sample size and objectives. In the studies by Abur (2014), King'endo (2010), Mukhandia (2014), Nyatuoro (2012) and Njoki (2013), both probability and non -probability sampling methods were used with specific techniques being stratified, cluster, purposive, systematic and random sampling. Furthermore, descriptive research design was adopted where by data was collected through questionnaires, key informant interviews and focused group discussions which were personally administered by the concerned researchers after which data was summarized and finally presented through graphs, pie charts, means, frequency tables and standard deviations. The inferential statistics used were chi square, ANOVA and correlation.

However, the methodologies adopted had some few challenges for instance, during focused group discussion participants were not comfortable sharing their information on drugs and substance abuse; therefore, they chose to keep some vital information to themselves for fear of victimization and associated stigma from fellow students being that illicit drug ad substance use is punishable by authority. Therefore, this limited the amount and quality of data collected.

Additionally, closed ended questionnaires were used and administered by the interviewers thus limiting the freedom of the respondents to freely give in depth information since some feared eye-contact with the interviewer and not comfortable answering the questions but would freely do so if the questionnaires were self-administered and open ended.

Furthermore data collection process was time consuming and tiresome being that the researchers had to personally administer the questionnaires to each respondent rather than letting them fill questionnaires by themselves upon giving instructions. Finally, the study sample never included parents or students family in the study whereby the focus was majorly on the students and school hence not getting data on parental and family influence on drug and substance abuse among students which is very key in coming up with suitable strategies to address the problem.

In order to avoid the above mentioned shortcomings, this study therefore adopted a more improved methodology as outlined in chapter below.

\section{Material Studied}

The target population for this study were all youths aged 15-25 years in secondary schools within Kisumu East Sub County. For in depth understanding of the drug and substance issue, sampled household heads were included from each ward as key informants.

\subsection{Study Area Description}

The study was conducted in Kisumu East Sub County in Kisumu County within the community set up. The area has approximated total population of 220,997 with an area of 141.6 sq.km density of 1560 per sq.km with a total number of 61,388 households. It is made up of five wards namely; Kolwa East, Kolwa Central, Nyalenda B, Kajulu and Manyatta B ward each having two village units namely; Kasule, Nyalunya, Kajulu East and West, Kanyakwar, Kowino, Dago, Kuoyo, Kawese and Chiga. The area has a total of 33 secondary schools with a total population of 26,000 students out of which 12,800 are males and 13,200 females. Out of 33 schools, 28 are day schools drawing students from the community.

The main economic activities are quarrying, motorcycle ride, small scale businesses and farming.

Problems faced by the residents include: Poor waste management, drugs and substance abuse, high crime rate, school drop- out, poverty, insecurity and teenage pregnancy. Based on the needs prioritization, drugs and substance abuse is such a big challenge. The rate at which students drop out of school is alarming and the main reason being drug and substance abuse necessitated by the easy availability of drugs in the area as well as the geographical location. There are homes where bhang as well as local brew is sold at affordable cost. If the problem is not addressed soon, the damage will be great not only to the youths but to the entire country.

\subsection{Methods and/or Techniques}

This was a descriptive cross-sectional study design on the socio-cultural and economic predictors of drugs and substance abuse among high school students aged between 15-25 years and learning in secondary schools within 
the study area. The study sample was 434 comprising of 394 high school students and 40 household heads residing within Kisumu East Sub County for not less than six months. The sample size was determined using Yamane formula (1967) expressed mathematically thus:

$$
\mathrm{n}=\frac{\mathrm{N}}{1+\mathrm{N} e^{2}}
$$

Where: $n=$ sample size required

$$
\begin{aligned}
& \mathrm{N}=\text { target population } \\
& \mathrm{e}=\text { maximum acceptable margin of error/ allowable error \% } \\
& \mathrm{N}=26,000 \quad \mathrm{e}=0.05 \\
& \qquad \mathrm{n}=\frac{26,000}{1+26,000 * 0.05^{2}}=394 .
\end{aligned}
$$

Allowance of $10 \%$ was made to cover for non -response making the sample size to be 434 . Apart from the 394 students, 40 household heads were included as key informants.

The study adopted both probability and non -probability sampling procedures with specific sampling techniques being snow ball, random, cluster and stratified sampling. The area was clustered in to wards and village units after which stratified sampling was applied to sample the students based on gender and age while household heads were randomly selected from each ward based on allocation per ward. Students were identified through Snowball technique where by the identified students gave direction on the next households with secondary students within the community until the required number of students per ward was met. The same technique was applied in identifying other known students who are involved in drug and substance abuse.

Before actual study began, the research instruments / tools were tested and re-tested for both reliability and validity in a different area to analyze if the results are correct, consistent and meeting the intended purpose. The study objectives were clearly defined to the respondents without being pressured in any way to select specific choices among the answer sets. The research instruments included: questionnaires, informed consent forms for those aged 18 and above, assent forms for those aged 15-17 accompanied by parental/guardian's permission forms authorizing their children to participate in the study. All these were designed in English with native language translation.

Authority to conduct this study was obtained from the Board of Postgraduate Studies, JOOUST thereafter ethical approval and clearance from the JOOTRH Ethics Review Committee and NACOSTI. Permission to conduct the study in the area was sought from the area local administration. Prior to enrolment, the purpose of the study as well as the implications was explained to all prospective study participants and written informed consent as well as assent obtained from all willing to take part in the study before the study commenced. The study participants were assured of confidentiality of both their information and identities. Due diligence was accorded the entire data collection process given the sensitive nature of the study participants in order to prevent any perception of stigmatization of the participants. Study findings were relayed to the community through feedback meetings at the community level and ministry of education. Data was collected using both structured and open ended selfadministered questionnaires and observation. The student and household questionnaires were designed in English with native language translation; respondents with difficulty filling the questionnaire were assisted by the researcher and the trained research assistants in language best understood by them. The questionnaires were tested for both validity and reliability through pilot study in a different area and were confirmed to be consistent, clear and addressed the intended purpose before finally using them in the study area. The respondents were briefed on the study purpose, their rights and obligation. Reliability was analyzed through Cronbach's Alpha $(\alpha)$ Reliability Coefficient Test to establish the extent to which the content of the questionnaire were consistent in enlisting same responses every time the instrument are administered. For this study, the instruments scored an alpha value of 0.7 which was sufficiently reliable. Observation was used to collect data on non -verbal communication displayed through body language such as facial expression, behavior and assessment of living condition.

The data was organized and summarized through tables. Inferential statistics were done using Chi square to test for relationship between two categorical variables while study out-come variables analyzed through binomial logistic regression. Multiple regression analysis (multivariable regression) was used to predict the value of dependent variable based on the value of two or more other predictor variables. Data from observation were analyzed through content and narrative analysis. $\mathrm{P}$ value $<0.05$ was considered statistically significant. All 
materials used to acquire data were kept under lock, and only limited access by researcher and data analyst permitted. Analyzed data was equally stored in password-protected computers, with no access to anyone not directly involved with data management awaiting dissemination to the relevant authorities and publishing for public consumption.

\section{Results}

The study sample size was $434 ; 394$ students and 40 household heads respectively. Out of the 394 students, 358 filled the questionnaire while 36 did not because 20 had travelled to upcountry due to Corona pandemic while 16 completely refused to participate in the study due to personal reasons thus reducing the sample size to 398 . A response rate of $91 \%$ was achieved which was statistically enough for analysis and reporting. To provide a bit more information about the abuse of drugs and substance among the high school students, the 40 household heads were interviewed as key informants.

\subsection{Demographic Characteristics of students-Kisumu East Sub-County}

A total of 358 students were enrolled in the study, whose characteristics are presented in Table 1. Majority of the study participants $217(60.61 \%)$ were aged between 15-17 years. More than half 184 (51.40\%) of the participants were female. The highest number $274(76.54 \%)$ of the respondents were Christians. One hundred and fifty (41.90\%) of the students were residents of Kolwa Central with a small number 11 (3.07\%) came from Manyatta B. Most of the participants, 229 (63.97\%) were from mixed day secondary schools with only three $(0.84 \%)$ from mixed boarding schools (Table 1). Overall, the highest number $138(38.55 \%)$ of the participants were students of form two class.

Table 1. Demographic characteristics of students, Kisumu East Sub-County $(\mathrm{N}=358)$

\begin{tabular}{|c|c|}
\hline Demographic Characteristics & $\mathrm{n}(\%)$ \\
\hline \multicolumn{2}{|l|}{ Age category } \\
\hline $15-17$ years & $217(60.61)$ \\
\hline $18-24$ years & $135(37.71)$ \\
\hline$\geq 25$ years & $6(1.68)$ \\
\hline \multicolumn{2}{|l|}{ Gender } \\
\hline Male & $174(48.60)$ \\
\hline Female & $184(51.40)$ \\
\hline \multicolumn{2}{|l|}{ Religion } \\
\hline Christianity & $274(76.54)$ \\
\hline Islamic & $72(20.11)$ \\
\hline Atheist & $1(0.28)$ \\
\hline Hinduism & $6(1.68)$ \\
\hline Others & $5(1.40)$ \\
\hline \multicolumn{2}{|l|}{ Ward } \\
\hline Nyalenda A & $57(15.92)$ \\
\hline Kajulu & $75(20.95)$ \\
\hline Kolwa East & 65 (18.16) \\
\hline Kolwa Central & $150(41.90)$ \\
\hline Manyatta B & $11(3.07)$ \\
\hline \multicolumn{2}{|l|}{ School Category } \\
\hline Boys Day & 49 (13.69) \\
\hline Boys Boarding & $15(4.19)$ \\
\hline Mixed Day & $229(63.97)$ \\
\hline Girls Day & $42(11.73)$ \\
\hline Girls Boarding & $20(5.59)$ \\
\hline
\end{tabular}




$\begin{array}{ll}\text { Mixed Boarding } & 3(0.84) \\ \text { Form } & \\ \text { One } & 69(19.27) \\ \text { Two } & 138(38.55) \\ \text { Three } & 91(25.42) \\ \text { Four } & 60(16.76)\end{array}$

\subsection{Demographic characteristics of household heads -Kisumu East Sub-County}

To assess strategies used by parents to prevent abuse of drugs among the students, this study used data from the key informants. The data for the individual characteristics of the key informants are presented in the Table 2. Among the selected key informants, the majority were above 40 years $24(60 \%)$ and most of them $23(57.50 \%)$ were female. In terms of religion, 29 (72.5\%) were Christians and only 11 (27.5\%) were Islamic. The least number of these respondents were residents of Kolwa East $6(15 \%)$. Close to three quarters of the household heads were married $25(62.5 \%)$ and higher proportion of them had a university education 14 (35\%) (Table 2).

Table 2. Demographic characteristics of household heads Kisumu East Sub-County $(\mathrm{N}=40)$

\begin{tabular}{ll}
\hline Demographic Characteristics & \multicolumn{1}{c}{$\mathrm{n}(\%)$} \\
\hline Age category & $6(15.00)$ \\
$26-35$ years & $10(25.00)$ \\
$36-40$ years & $24(60.00)$ \\
$>40$ years & \\
Gender & $17(42.50)$ \\
Male & $23(57.50)$ \\
Female & \\
Religion & $29(72.50)$ \\
Christianity & $11(27.50)$ \\
Islamic & \\
Ward & $8(20.00)$ \\
Nyalenda A & $11(27.50)$ \\
Kajulu & $6(15.00)$ \\
Kolwa East & $8(20.00)$ \\
Kolwa Central & $7(17.50)$ \\
Manyatta B & \\
Marital Status & $25(62.50)$ \\
Married & $5(12.50)$ \\
Single & $3(7.50)$ \\
Divorced & $7(17.50)$ \\
Widowed & \\
Education level & $7(17.50)$ \\
Primary & $7(17.50)$ \\
Secondary & $12(30.00)$ \\
College & $14(35.00)$ \\
\hline & \\
\hline & \\
\hline
\end{tabular}


4.3 Socio-cultural and economic factors influencing the abuse of drugs and substance among students in Kisumu East Sub-County

To reveal socio-cultural and economic factors associated with the abuse of drugs and substance, this study compared the participants' socio-cultural and economic characteristics with the outcome of abuse of drugs. Table 3 presents summary of the association between the socio-economic characteristics and abuse of drugs and substance. Parental expectations $<0.001$, psychological disorders or mental problems $<0.001$, family background $<0.001$, leisure activities and festivities $<0.001$, number of siblings in the family $<0.001$, cultural beliefs and practices 0.04 , birth position of the student $<0.001$, family shock and the need to treat certain ailments $<0.001$ were found to be significantly associated with the abuse of drugs and substance $(p<0.05)$. However, social factors such as parenting style, frustrations and stress at home, parent-child relationship, presence of addicted person in the family among other factors did not detect any significant association. This study reports significant association between economic factors with abuse of drugs and substance except for the family income status and cheap cost of drugs.

Table 3. Socio-cultural and economic factors associated with drug and substance abuse among high students

\begin{tabular}{|c|c|c|c|c|}
\hline \multirow[b]{2}{*}{ Socio-cultural and Economic factors } & \multirow[b]{2}{*}{$\begin{array}{ll}\text { All } & \mathrm{N}=358 \\
\mathrm{n}(\%) & \end{array}$} & Drug and Substance use & \multirow[b]{2}{*}{$\begin{array}{l}\text { No } \\
\mathrm{n}(\%)\end{array}$} & \multirow[b]{2}{*}{ p-Value } \\
\hline & & $\begin{array}{l}\text { Yes } \\
\mathrm{n}(\%)\end{array}$ & & \\
\hline \multicolumn{5}{|l|}{ Socio-cultural factors } \\
\hline Parenting Style & $288(80.45)$ & $171(78.08)$ & $117(84.17)$ & 0.16 \\
\hline Parental expectations & $243(67.88)$ & $189(86.30)$ & $54(38.85)$ & $<0.001$ \\
\hline Parental/Guardian's attitude towards drugs & $268(74.86)$ & $156(71.23)$ & $112(80.58)$ & 0.05 \\
\hline Frustrations and stress at home & $293(81.84)$ & $173(79.00)$ & $120(86.33)$ & 0.08 \\
\hline Psychological disorders/mental problems & $159(44.41)$ & $79(36.07)$ & $80(57.55)$ & $<0.001$ \\
\hline Parent-child relationship & $307(85.75)$ & $183(83.56)$ & $124(89.21)$ & 0.14 \\
\hline Family background/history of drug abuse & $146(40.78)$ & $71(32.42)$ & $75(53.96)$ & $<0.001$ \\
\hline Leisure activities and festivities & $151(42.18)$ & $65(29.68)$ & $86(61.87)$ & $<0.001$ \\
\hline Presence of addicted person in the family & $240(67.04)$ & $145(66.21)$ & $95(68.35)$ & 0.68 \\
\hline Influence from family and relatives & $264(73.74)$ & $155(70.78)$ & $109(78.42)$ & 0.11 \\
\hline Ease access of drugs & $267(74.58)$ & $165(75.34)$ & $102(73.38)$ & 0.68 \\
\hline Household size & $116(32.40)$ & $66(30.14)$ & $50(35.97)$ & 0.25 \\
\hline Number of siblings & $112(31.28)$ & $71(32.42)$ & $41(29.50)$ & $<0.001$ \\
\hline Birth position and spacing & $84(23.46)$ & $47(21.46)$ & $37(26.62)$ & 0.26 \\
\hline \multicolumn{5}{|l|}{ Birth position } \\
\hline First & $164(45.81)$ & $111(50.68)$ & $53(38.13)$ & \multirow{4}{*}{$<0.001$} \\
\hline Second & $107(29.89)$ & $56(25.57)$ & $51(36.69)$ & \\
\hline Third & $64(17.88)$ & $33(15.07)$ & $31(22.30)$ & \\
\hline Fourth & $4(1.12)$ & $19(8.68)$ & $4(2.88)$ & \\
\hline Family Shock & $175(48.88)$ & $87(39.73)$ & $88(63.31)$ & $<0.001$ \\
\hline Cultural beliefs and practices & $149(41.62)$ & $82(37.44)$ & $67(48.20)$ & 0.04 \\
\hline Need to treat certain ailments & $131(36.59)$ & $57(26.03)$ & $74(53.24)$ & $<0.001$ \\
\hline \multicolumn{5}{|l|}{ Economic factors } \\
\hline \multicolumn{5}{|l|}{ Family income status (Ksh) } \\
\hline Below 30000 & $132(36.87)$ & $69(31.51)$ & $63(45.32)$ & \multirow{4}{*}{0.06} \\
\hline $31000-50000$ & $90(25.14)$ & $60(27.40)$ & $30(21.58)$ & \\
\hline $51000-100000$ & $116(32.40)$ & $78(35.62)$ & $38(27.34)$ & \\
\hline$>100000$ & $20(5.59)$ & $12(5.48)$ & $8(5.76)$ & \\
\hline
\end{tabular}




\begin{tabular}{lllll}
\hline Father's occupation & & & & \\
Employed & $194(54.19)$ & $133(60.73)$ & $61(43.88)$ & \\
Self-employed & $47(13.13)$ & $19(8.68)$ & $28(20.14)$ & $<0.001$ \\
Others & $117(32.68)$ & $67(30.59)$ & $50(35.97)$ & \\
Mother's occupation & & & $53(38.13)$ & \\
Employed & $161(44.97)$ & $108(49.32)$ & $6(4.32)$ & 0.04 \\
Unemployed & $11(3.07)$ & $5(2.28)$ & $31(22.30)$ & \\
Self-employed & $87(24.30)$ & $56(25.57)$ & $49(35.25)$ & \\
Others & $99(27.65)$ & $50(22.83)$ & $9(4.11)$ & \\
Guardian's occupation & & & 0 & \\
Employed & $32(8.94)$ & $23(16.55)$ & $15(6.85)$ & \\
Unemployed & $4(1.12)$ & $4(2.88)$ & $195(89.04)$ & \\
Self-employed & $21(5.87)$ & $6(4.32)$ & $118(84.89)$ & \\
Others & $301(84.08)$ & $106(76.26)$ & $5(3.60)$ & $<0.001$ \\
Employment status & & & $16(11.51)$ & \\
Full time & $306(85.47)$ & $188(85.84)$ & $63(45.32)$ & $<0.001$ \\
Part time & $29(8.10)$ & $24(10.96)$ & $75(53.96)$ & 0.05 \\
Others & $23(6.42)$ & $7(3.20)$ & \\
More pocket money & $117(32.68)$ & $54(24.66)$ & \\
Cheap cost of drugs & $170(47.49)$ & $95(43.38)$ & \\
\hline
\end{tabular}

\subsection{Socio-Cultural and Economic Predictors of Drug and Substance Abuse among High School Students}

Results from the binomial logistic regression reveals that students whose parents had high academic expectations $(\mathrm{OR}=9.92 ; 95 \% \mathrm{CI}, 5.93-16.59)$, students who had ease access to drugs $(\mathrm{OR}=1.11 ; 95 \% \mathrm{CI}, 0.68-1.80)$, students from households with high number of siblings $(\mathrm{OR}=1.15 ; 95 \% \mathrm{CI}, 0.72-1.82)$ were more likely to abuse drugs and substance (Table 4). In terms of economic factors, this study reports higher odds among students whose family income ranges between 31000 and $50000(\mathrm{OR}=1.83$; 95\% CI, 1.05-3.18), 51000-100000 (OR=1.87; 95\% CI, 1.12-3.14) or above one hundred thousand ( $\mathrm{OR}=1.37 ; 95 \% \mathrm{CI}, 0.53-3.57)$ respectively. Also, students whose parents had part time source of income $(\mathrm{OR}=3.01 ; 95 \% \mathrm{CI}, 1.12-8.11)$ were more likely to abuse drugs and substance as compared to those whose parents had full time jobs.

When this study controlled for potential confounders such as parental expectations, psychological disorders, family background, leisure activities and among other factors in the multiple regression model, abuse of drugs and substance_was significantly more likely among students whose parents had high academic expectations $\left.{ }_{\mathrm{a}} \mathrm{OR}=17.13 ; 95 \% \mathrm{CI} 8.30,35.37\right)$, students who had psychological or mental problems $\left({ }_{\mathrm{a}} \mathrm{OR}=3.68 ; 95 \% \mathrm{CI} 1.34\right.$, 10.11), students whose family income ranged between $31000-50000\left({ }_{\mathrm{a}} \mathrm{OR}=2.91 ; 95 \% \mathrm{CI} 1.38,6.13\right)$ or students whose parents had part time source of income $\left({ }_{\mathrm{a}} \mathrm{OR}=4.30 ; 95 \%\right.$ CI 1.43, 12.95) (Table 4.6). Also, abuse of drugs and substance was more likely among students whose family income ranged between 51000 and 100000 $\left({ }_{\mathrm{a}} \mathrm{OR}=1.59 ; 95 \% \mathrm{CI} 0.61,4.17\right)$, students whose mothers were unemployed $\left({ }_{\mathrm{a}} \mathrm{OR}=1.46 ; 95 \% \mathrm{CI} 0.22,9.66\right)$ or self-employed $\left({ }_{\mathrm{a}} \mathrm{OR}=1.06 ; 95 \% \mathrm{CI} 0.44,2.56\right)$ though the effects were not statistically significant. Moreover, this study confirms increased odds among students living with guardians that were self-employed $\left({ }_{\mathrm{a}} \mathrm{OR}=4.28 ; 95 \% \mathrm{CI}\right.$ $0.95,19.41)$ or guardians with other source of living $\left({ }_{a} \mathrm{OR}=2.24 ; 95 \% \mathrm{CI} 0.74,6.80\right)$. However, students whose family income was more than one hundred thousand $\left({ }_{a} \mathrm{OR}=0.49 ; 95 \%\right.$ CI $\left.0.14,1.70\right)$ were associated with lower odds of abusing drugs and substance after adjusting for other covariates.

Family background $(\mathrm{OR}=0.88 ; 95 \%$ CI $0.34,2.31)$, number of siblings $\left({ }_{\mathrm{a}} \mathrm{OR}=0.58 ; 95 \% \mathrm{CI} 0.24,1.41\right)$, family shock $\left({ }_{a} \mathrm{OR}=0.52 ; 95 \%\right.$ CI $\left.0.25,1.08\right)$ and need to treat certain ailments $\left({ }_{a} \mathrm{OR}=0.70 ; 95 \%\right.$ CI $\left.0.15,3.19\right)$ were not significantly associated with the abuse of drugs and substance after adjusting for other covariates (Table 4). 
Table 4. Socio-cultural and economic predictors of drug and substance abuse among high school students

\begin{tabular}{|c|c|c|c|c|c|}
\hline \multirow[b]{2}{*}{ Socio-cultural and Economic predictors } & \multicolumn{2}{|c|}{ Drug and Substance use } & \multirow[b]{2}{*}{$\begin{array}{l}\text { Crude Odds } \\
\text { Ratio }(95 \% \mathrm{CI})\end{array}$} & \multirow[b]{2}{*}{$\begin{array}{l}\text { Adjusted Odds } \\
\text { Ratio }(95 \% \mathrm{CI})\end{array}$} & \multirow[b]{2}{*}{ p-Value } \\
\hline & $\begin{array}{l}\text { Yes } \\
(n=219) \\
n(\%)\end{array}$ & $\begin{array}{l}\text { No }(n=139) \\
n(\%)\end{array}$ & & & \\
\hline \multicolumn{6}{|l|}{ Socio-cultural factors } \\
\hline Parenting Style & $288(80.45)$ & $171(78.08)$ & $0.67(0.38,1.17)$ & & \\
\hline Parental expectations & $243(67.88)$ & $189(86.30)$ & $9.92(5.93,16.59)$ & $17.13(8.30,35.37)$ & $<0.001$ \\
\hline Parental/Guardian's attitude towards drugs & $268(74.86)$ & $156(71.23)$ & $0.60(0.36,1.00)$ & & \\
\hline Frustrations and stress at home & $293(81.84)$ & $173(79.00)$ & $0.60(0.33,1.07)$ & & \\
\hline Psychological disorders/mental problems & $159(44.41)$ & $79(36.07)$ & $0.42(0.27,0.64)$ & $3.68(1.34,10.11)$ & 0.01 \\
\hline Parent-child relationship & $307(85.75)$ & $183(83.56)$ & $0.61(0.32,1.17)$ & & \\
\hline Family background/history of drug abuse & $146(40.78)$ & $71(32.42)$ & $0.41(0.26,0.63)$ & $0.88(0.34,2.31)$ & 0.8 \\
\hline Leisure activities and festivities & $151(42.18)$ & $65(29.68)$ & $0.26(0.17,0.41)$ & $0.23(0.10,0.54)$ & $<0.001$ \\
\hline Presence of addicted person in the family & $240(67.04)$ & $145(66.21)$ & $0.91(0.58,1.43)$ & & \\
\hline Influence from family and relatives & $264(73.74)$ & $155(70.78)$ & $0.67(0.41,1.10)$ & & \\
\hline Ease access of drugs & $267(74.58)$ & $165(75.34)$ & $1.11(0.68,1.80)$ & & \\
\hline Household size & $116(32.40)$ & $66(30.14)$ & $0.77(0.49,1.21)$ & & \\
\hline Number of siblings & $112(31.28)$ & $71(32.42)$ & $1.15(0.72,1.82)$ & $0.58(0.24,1.41)$ & 0.23 \\
\hline Birth position and spacing & $84(23.46)$ & $47(21.46)$ & $0.75(0.46,1.24)$ & & \\
\hline \multicolumn{6}{|l|}{ Birth position } \\
\hline First & $164(45.81)$ & $111(50.68)$ & Ref & & \\
\hline Second & $107(29.89)$ & $56(25.57)$ & $0.52(0.32,0.87)$ & & \\
\hline Third & $64(17.88)$ & $33(15.07)$ & $0.51(0.28,0.92)$ & & \\
\hline Fourth & $4(1.12)$ & $19(8.68)$ & 0 & & \\
\hline Fifth & & & 0 & & \\
\hline Family Shock & $175(48.88)$ & $87(39.73)$ & $0.38(0.25,0.59)$ & $0.52(0.25,1.08)$ & 0.08 \\
\hline Cultural beliefs and practices & $149(41.62)$ & $82(37.44)$ & $0.64(0.42,0.99)$ & & \\
\hline Need to treat certain ailments & $131(36.59)$ & $57(26.03)$ & $0.31(0.20,0.48)$ & $0.70(0.15,3.19)$ & \\
\hline
\end{tabular}

\section{Economic factors}

Family income status (Ksh)

Below 30000

31000-50000

51000-100000

$>100000$

Father's occupation

Employed

Self-employed

Others

$132(36.87) \quad 69(31.51) \quad$ Ref

$90(25.14) \quad 60(27.40) \quad 1.83(1.05,3.18) \quad 2.91(1.38,6.13) \quad \mathbf{0 . 0 1}$

$116(32.40) \quad 78(35.62) \quad 1.87(1.12,3.14) \quad 1.59(0.61,4.17) \quad 0.35$

$20(5.59) \quad 12(5.48) \quad 1.37(0.53,3.57) \quad 0.49(0.14,1.70) \quad 0.26$

Mother's occupation

Employed

Unemployed

Self-employed

$133(60.73) \quad 61(43.88) \quad$ Ref

$19(8.68) \quad 28(20.14) \quad 0.31(0.16,0.60) \quad 0.15(0.06,0.36) \quad<0.001$

Others

$67(30.59) \quad 50(35.97) \quad 0.61(0.38,0.99)$

$0.74(0.35,1.54) \quad 0.42$ $161(44.97) \quad 108(49.32) \quad$ Ref

$\begin{array}{lllll}11(3.07) & 5(2.28) & 0.41(0.12,1.40) & 1.46(0.22,9.66) & 0.7\end{array}$

$\begin{array}{lllll}87(24.30) & 56(25.57) & 0.89(0.51,1.53) & 1.06(0.44,2.56) & 0.9\end{array}$

$99(27.65) \quad 50(22.83) \quad 0.50(0.30,0.84) \quad 0.46(0.19,1.08) \quad 0.07$ 


\begin{tabular}{llllll}
\hline $\begin{array}{l}\text { Guardian's occupation } \\
\text { Employed }\end{array}$ & $32(8.94)$ & $23(16.55)$ & Ref & & \\
Unemployed & $4(1.12)$ & $4(2.88)$ & 0 & 0 & \\
Self-employed & $21(5.87)$ & $6(4.32)$ & $6.39(1.88,21.66)$ & $4.28(0.95,19.41)$ & 0.06 \\
Others & $301(84.08)$ & $106(76.26)$ & $4.70(2.10,10.53)$ & $2.24(0.74,6.80)$ & 0.15 \\
\hline Employment status & & & & & \\
Full time & $306(85.47)$ & $188(85.84)$ & Ref & & \\
Part time & $29(8.10)$ & $24(10.96)$ & $3.01(1.12,8.11)$ & $4.30(1.43,12.95)$ & $\mathbf{0 . 0 1}$ \\
Others & $23(6.42)$ & $7(3.20)$ & $0.27(0.11,0.69)$ & $0.47(0.14,1.56)$ & 0.21 \\
More pocket money & $117(32.68)$ & $54(24.66)$ & $0.39(0.25,0.62)$ & $0.29(0.13,0.62)$ & $<0.001$ \\
Cheap cost of drugs & $170(47.49)$ & $95(43.38)$ & $0.65(0.43,1.00)$ & $0.85(0.44,1.61)$ & 0.61 \\
\hline
\end{tabular}

\section{Discussion}

\subsection{Household Socio-Cultural and Economic Predictors of Drug and Substance Abuse among High School Students}

\subsubsection{Socio-Cultural Predictors}

Parental expectations, psychological disorders or mental problems, family background, leisure activities and festivities, number of siblings in the family, cultural beliefs and practices, birth position of the student, family shock and the need to treat certain ailments were found to be significantly associated with the abuse of drugs and illicit substance $(p<0.05)$. However, social factors such as parenting style, frustrations and stress at home, parent-child relationship, presence of addicted person in the family among other factors did not detect any statistical significant association.

This study reveals that abuse of drugs and substance was significantly 17.13 times more likely among students whose parents had too much academic expectations $\left({ }_{a} \mathrm{OR}=17.13 ; 95 \%\right.$ CI 8.30, 35.37) because these parents/ guardians expect their children to achieve highest level of academic excellence in order to make them proud regardless of their academic ability. Since no parent/ guardian would be impressed with poor performance from their children, they push them so hard to score good grades to an extent of even punishing them severely hoping that they improve next time. Unfortunately, not all students have that high intellectual capacity for excellent performance to parent's/guardian's.expectation. When the pressure becomes too much, these students choose to engage in to drugs and substance abuse as a way of dealing with unbearable situation at home. This finding disagrees with the study by Nyatuoro, (2012) which showed that high academic expectation by parents was associated with lowered risk of drugs and other substance abuse among students.

Similarly, higher odds were also registered among students who had pre-existing psychological or mental problems $\left({ }_{\mathrm{a}} \mathrm{OR}=3.68 ; 95 \%\right.$ CI $\left.1.34,10.11\right)$ this is because symptoms of mental or psychological problems are usually disruptive or uncomfortable pushing the students to use of alcohol and other substances as a form of self medication hoping for relief. Unfortunately, these drugs do very little to address the underlying mental symptoms but instead create a whole batch of problems increasing severity of the original mental health problem. Such students are 3.68 times more likely to abuse drugs and other substances compared to their counterparts without pre-existing psychological conditions. This is in agreement with findings by Mukhandia, (2014) parents with own mental issues to deal with find it very difficult to interact and supervise the adolescent in their mental state leading in to reversed roles with many adolescents taking care of their parents something that push them in to drug and substance abuse as a copping mechanism. Some of these pre-existing mental problems may be passed on to the children genetically prompting them to engage in drug and substance abuse as a way of managing the uncomfortable effects of the mental problems. For instance students using alcohol or other sedative drugs to deal with stress or depression, some using alcohol or bhang to deal with social anxiety in social situation.

The findings further point that students from households with high number of siblings ( $\mathrm{OR}=1.15 ; 95 \% \mathrm{CI}$, 0.72-1.82) were 1.15 times more likely to abuse drugs and substance due to the influence from the older siblings since the younger siblings usually believe in and copy everything done by the older siblings whom they feel are always right and informed than them. This was most likely in households where first born is a drug addicts while students who had ease access to drugs and substances were 1.1 times more likely to abuse them because they could get them anytime they feel like (OR=1.11; 95\% CI, 0.68-1.80). The findings is in agreement with that of Cheloti, 
(2013); Chebukaka, (2014); Nyatuoro, (2012) which showed that students with more than nine siblings were at a higher risk of engaging in drug and substance abuse than those with fewer siblings while younger siblings were introduced in to drugs by older siblings who were already engaged in to the habit.

Cultural beliefs and practices were also found to be statistically associated with the abuse of drugs and substance abuse. This finding concurs with that of Kasundu et al., (2012) and Simatwa et al., (2014). Some cultures openly promote and recommend taking of stimulants, depressants and hallucinogens such as beer, liquor, wine, tobacco and cannabis sativa during particular important cultural and ceremonial occasions like marriage, memorial services, initiation and circumcision. Such ceremonies have unchecked drinking that goes unchallenged while some parents indulge in drug use in the presence of their children thus predisposing them to the vice.

Family shock such as sudden drop in family income, parental job retrenchment, suicidal or mysterious deaths in the family, death of bread winner were found to be contributing factors in the likelihood of a student to engage in drugs and substance abuse as the only way of dealing with the un bearable circumstances in the family. Though not statistically significant, $67 \%$ of the students confirmed they had drug addicted family members or relatives who influenced them in to the habit by making them feel that drugs are cool through displaying positive attitude towards the abuse. In homes where any of the family members is a drug addict, these substances are stored in the house where the students can access them without struggle.

\subsubsection{Household Economic Predictors}

Family income, Employment status, a lot of pocket money as well as parental / guardians' occupation were found to be to be significantly associated with the abuse of drugs and substance $(p<0.05)$.

Consistent with previous studies by McMorris et al., (2011); Atherton et al., (2016); Baltazar et al., (2016); Handren et al., (2016); Jahanshahloo et al., (2016); Miller and Cook, (2017), this study shows that students from families with income between Ksh 31,000- 50,000 $\left({ }_{\mathrm{a}} \mathrm{OR}=2.91\right.$; $95 \%$ CI 1.38, 6.13) were found to be 2.91 times more likely to abuse drugs and other substances compared to other groups. Similarly, family income between $51,000-100,000$ registered increased odds of $\left({ }_{\mathrm{a}} \mathrm{OR}=1.59 ; 95 \%\right.$ CI $\left.0.61,4.17\right)$. This may be linked to the fact that most probably such parents/ guardians are employed and as such have to leave home early and return late from work due to high job demands leaving them with very minimal time to attend to their children's needs be it social, psychological or academic. Failure of the parents to timely attend to these needs gives room for the children to find support and guidance from other people most likely house servants or friends with whom much time is spent and in the long run misguide and even lure them in to drugs and substance abuse as a way of managing their life challenges. Unfortunately, the parents/guardians may fail to detect any change in the students behavior early enough to prevent the vice before it gets worst because they hardly interact with them due to job demand.

Moreover, this study confirms increased odds among students living with guardians that are self-employed ${ }_{(a} \mathrm{OR}=4.28 ; 95 \%$ CI $\left.0.95,19.41\right)$ who confirmed to be 4.28 times more likely to engage in to abuse of drugs and other substances. Self- employment is usually demanding since those involved have no any other source of income to supplement their daily in come. In order to maintain the source of livelihood, they have to work extra hard even if it means working for 24 hours thus robbing them of family time during which they can attend to the varied needs of the children and other members. This is in agreement with findings by Gale et al., (2012); NACADA, (2012); Mukhandia, (2014); Simatwa et al., (2014) busy work schedules and long working hours of family members leads to limited family time for parents to bond and supervise their children.

Consistent with study findings by Njoki, (2013); Simatwa et al., (2014); Sajjadi et al., (2015); Shahraki et al., (2019), students who received unnecessary generous amount of pocket money were also more likely to abuse drugs and substance abuse compared to those who never received any because they have more cash at hand which they use to buy these drugs or even join other friends at entertainment joints where drugs and other substances are served without supervision.

\section{Conclusion}

Drug and substance abuse is a major public health problem among all age groups worldwide with substantial impact on human health and well-being ranging from medical, social, economic and political consequences. Due to its magnitude, it calls for concerted effort by parents, community, ministry of health and education as well as all other stakeholders for the attainment of the Sustainable development Goals as well as the vision 2030 which aims at making Kenya industrial and mid-level income country. Lack of parental/ guardian's supervision and monitoring of the students movements, poor parent-child attachment due to inadequate family time, no communication on the dangers of drugs and substance abuse to students by the parents and high academic expectations by parents/ guardians from students are the major contributors of drugs and substance abuse among 
students.

\subsection{Recommendations}

There is need for parents / guardians to balance between work and family time in order to build strong attachment with the children and timely address their concerns. This will ensure sufficient monitoring of their movements and act promptly should there be anything unusual in their behavior.

\section{Authorship Contribution Statement}

All authors contributed to the study conception and design. Material preparation, data collection and analysis were performed by Mrs. Marceline Awino Orende, Mrs. Marion Agiza Muranda, while review and editing was done by Dr. David Otieno Odongo and Dr. Daniel Ogungu Onguru. The first draft of the manuscript was written by Mrs. Marceline Awino Orende, reviewed and edited by Mrs. Marion Agiza Muranda, Dr. David Otieno Odongo and Dr. Daniel Ogungu Onguru. All authors read and approved the final manuscript.

\section{Declaration Statements}

\section{Funding}

The Authors did not receive any grant for the study. The expenses for the study were funded by the corresponding author Mrs. Marceline Awino Orende.

\section{Ethical Approval}

Ethical approval was obtained from Jaramogi Oginga Odinga Teaching and Referral Hospital ERC and a study permit from National Commission for Science, Technology and innovation (NACOSTI).

\section{Informed Consent}

A written Informed consent and assent forms for participation and publish were obtained from respondents and the community members before starting the study.

\section{Acknowledgement}

Sincere gratitude to God for provision and good health throughout the manuscript development period, Board of Postgraduate Studies, JOOUST, the JOOTRH Ethics Review Committee and NACOSTI for review and approval of my proposal for this study, the publication committee for acceptance to publish this manuscript, my Supervisors and peers at the University extra-mural studies for the support and guidance towards the completion of this manuscript, the study area administration and respondents for the support and permission to conduct the study in the area and finally my beloved family for their love, prayers and encouragement throughout this manuscript development. God bless you all!

\section{Competing Interests Statement}

The authors declare no significant competing financial, professional or personal interests that might have influenced the performance or presentation of the work described in this manuscript.

\section{References}

Abbo, C., Okello, E. S., Muhwezi, W., Akello, G., \& Ovuga, E. (2016). Alcohol, substance use and psychosocial competence of adolescents in selected secondary schools in Uganda: A cross sectional survey. International neuropsychiatric disease journal, 7(2), 25387. https://doi.org/10.9734/INDJ/2016/25387

Abur, J. O. (2014). Drug and substance abuse among secondary school students. Embakasi District, Nairobi County. Retrieved from http://erepository. uonbi.ac.ke/bitstream/handle.pdf

Bandura, A., \& Walters, R. H. (1977). Social learning theory (Vol. 1). Prentice-hall Englewood Cliffs, NJ.

Bramness, J. G. (2014). [Intoxication, drugs, substance abuse and harmful use]. Tidsskr Nor Laegeforen, 134(20), 1968. https://doi.org/10.4045/tidsskr.14.0905

Brown, M. (2013). Familial, social, and individual factors contributing to risk for adolescent substance use. Journal of addiction, 2013. https://doi.org/10.1155/2013/579310

Chebukaka, R. N. (2014). Drug abuse among students in public secondary schools in Kenya, the case of Vihiga County. International Journal of Social Sciences and Education, 4(3).

Cheloti, S. K. (2013). Effectiveness of the HeadteachersStrategies Used to Curb drug and Substance Abuse in Public Schools in Nairobi County: Kenya (Unpublished M. Ed. Thesis, University of Nairobi).

Chesang, R. K. (2013). Drug abuse among the youth in Kenya. International journal of scientific \& technology 
research, 2(6), 126-131.

Cronbach, L. J. (1951). Coefficient alpha and the internal structure of tests. Psychometrika, 16(3), 297-334. https://doi.org/10.1007/BF02310555

Gale, J. A., Lenardson, M. H. S., Jennifer, D., Lambert PhD, D., \& Hartley PhD, M. H. A. (2012). Adolescent alcohol use: Do risk and protective factors explain rural-urban differences?

Hernandez, A. E., \& Araiza, S. M. (2014). Beliefs About Substance Abuse Among Adolescents: What Works?

Kalula, A. T. (2011). Cannabis use among young people in Dar es Salaam, Tanzania: a qualitative study. African Journal of Drug and Alcohol Studies, 10(1).

Kasundu, B., Mutiso, M., Sutter, C. P., \& Mwirigi, P. W. (2012). Factors contributing to drug abuse among the youth in Kenya: A Case of Bamburi Location.

Kiambi, M. J. (2018). Factors Influencing Drugs And Substance Abuse Among Public Secondary School Students In Kiambu County, Kenya. International Journal of Psychology, 3(1), 1-23.

King'endo, M. (2010). Incidence and extent of substance abuse among secondary school students in Nairobi Province, Kenya: implications for specialized intervention (Kenyatta University).

Momtazi, S., Nouhravesh, M., \& Taremian, F. (2009). A study of substance abuse and some related risk factors in Iranian high school students (Paper presented at the NIDA International Forum).

Mugenda, O. (2003). Research methods. Quantitative and qualitative approaches. Nairobi. Acts Press.

Mugenda O. M., \& Mugenda, A. G. (1999), (2013). Research Method-Quantitative and Qualitative approaches. Nairobi: Act Press.

Mukhandia, E. (2014). Determinants of drug abuse among secondary school students in Kenya, A case of Kabuchai Sub-County.

NACADA. (2012). Rapid situation assessment of the status of drug and substance abuse in Kenya.

NCPD. (2012).

Njoki, K. M. (2013). Drug and substance abuse in secondary schools in Kenya, Acase study of Kiambu County. UNIVERSITY OF NAIROBI.

Nyatuoro, J. O. (2012). Environmental and demographic factors influencing drug and substance abuse among secondary school students in Kisumu Town East, Kenya (Doctoral dissertation, Kenyatta University, Kenya).

Olumide, A. O., Robinson, A. C., Levy, P. A., Mashimbye, L., Brahmbhatt, H., Lian, L. H., ... \& Blum. (2014). Predictors of substance use among vulnerable adolescents in five cities: findings from the well-being of adolescents in vulnerable environments study. $J$ Adolesc Health, 55(6 Suppl), S39-47. https://doi.org/10.1016/j.jadohealth.2014.08.024

Sajjadi, H., Harouni, G. G., \& Sani, M. S. (2015). Personal, familial and environmental determinants of drug abuse: a causal-comparative study. Glob J Health Sci, 7(4), 367-374. https://doi.org/10.5539/gjhs.v7n4p367

Shahraki, G., Sedaghat, Z., \& Fararouei. M. (2019). Family and social predictors of substance use disorder in Iran: a case-control study. Subst Abuse Treat Prev Policy, 14(1), 17. https://doi.org/10.1186/s13011-019-0201-x

Simatwa, E. M.W., Odhong, S.O., Juma, S. L. A., \& Choka, G. M. (2014). Substance abuse among public secondary school students: Prevalence, strategies and challenges for public secondary school managers in Kenya: A case study of Kisumu East Sub County. 5(8), 315-330.

Stafström, M., \& Agardh, A. (2013). Socio-economic determinants for alcohol consumption and heavy episodic drinking in a Ugandan student population. The International Journal of Alcohol and Drug Research, 1(1), 57-67. https://doi.org/10.7895/ijadr.v1i1.40

WHO. (2019). Global status report on alcohol and health.

World Drug Report. (2014).

\section{Copyrights}

Copyright for this article is retained by the author(s), with first publication rights granted to the journal.

This is an open-access article distributed under the terms and conditions of the Creative Commons Attribution license (http://creativecommons.org/licenses/by/4.0/). 